\title{
Oscillations During Flow Boiling in Single Microchannels
}

\author{
Anže Sitar, ${ }^{1, *}$ Andrej Lebar, ${ }^{1,2}$ Michele Crivellari, ${ }^{3}$ Alvise Bagolini ${ }^{3}$ \\ and Iztok Golobič ${ }^{1}$ \\ ${ }^{1}$ University of Ljubljana, Faculty of Mechanical Engineering, Aškerčeva 6, 1000 Ljubljana, Slovenia. \\ ${ }^{2}$ University of Ljubljana, Faculty of Health Sciences, Zdravstvena pot 5, 1000 Ljubljana, Slovenia. \\ ${ }^{3}$ Fondazione Bruno Kessler, Center for Materials and Microsystems, Via Sommarive 18, I - 38123 Povo, Trento, Italy. \\ *Corresponding author: E-mail: anze.sitar@fs.uni-lj.si \\ phone: +38614771309
}

Received: 14-08-2018

\begin{abstract}
Flow boiling of degassed double-distilled water in a single $50 \times 50 \mu \mathrm{m}$ and $100 \times 50 \mu \mathrm{m}$ microchannel was investigated on the basis of experimental measurements and high-speed visualization. The visualized events during boiling were analyzed in terms of the bubble frequencies and boiling front oscillations in microchannels. A digital image sequence analysis algorithm was composed to determine the time dependence of bubble and meniscus locations. The results show (i) the dynamic characteristics of boiling in microchannels, (ii) the increase of fundamental oscillation frequencies with increasing heat flux and temperature of the microchannel bottom, (iii) the amplitudes of the flow boiling oscillations are inversely proportional to the fundamental frequencies. The outcomes of the study are important as the oscillations during boiling in single microchannels are experimentally confirmed to be predictable in terms of oscillation frequencies and amplitudes trends and dependencies. This knowledge is especially significant at constructing efficient two-phase micro heat exchangers, micro mixers or micro reactors, as the cross section and the length of the channel become exceedingly important design parameters in micro devices with boiling.
\end{abstract}

Keywords: Microchannels; flow boiling; oscillations; visualization; fundamental frequencies.

\section{Introduction}

Flow boiling in microchannels has the potential for achieving higher heat transfer coefficients compared to the single-phase liquid flow. However, boiling in microchannels is hindered by instabilities and early dryouts, which prevent wide implementation and overall heat transfer enhancement as presented by Kandlikar et al. ${ }^{1}$ Moreover, the incipience of boiling in microchannels requires high excess temperature difference between the channel wall and the bulk fluid as shown by Ghiaasiaan and Chedester ${ }^{2}$ and also Kandlikar. ${ }^{3}$ Accordingly, at the onset of nucleate boiling (ONB) the emerging bubble grows very rapidly due to the highly superheated liquid which was confirmed by Edel and Mukherjee. ${ }^{4}$ As the vapor bubble fills up the cross section of the microchannel it encounters all the heated walls, which occurs shortly after nucleation due to the small hydraulic diameters. The additional heated surface accelerates the bubble growth, which results in a highly instable flow with oscillations. The fluctuations of the working fluid during boiling present a severe challenge, especially when the vapor backflow becomes distinctive and hinders the forward flow of fresh liquid as shown by Barber et al. ${ }^{5}$ If the vapor backflow reaches the inlet manifold, it obstructs the liquid flow to all the channels connected to the manifold. It is therefore crucial to prevent pronounced vapor backflows in microchannels during flow boiling.

One of the possible solutions for flow stabilization during boiling is the incorporation of inlet restrictors between the inlet manifold and the microchannels (Kandlikar et al., ${ }^{6}$ Kuo and Peles, ${ }^{7}$ Wang et al., ${ }^{8}$ Sitar et al. ${ }^{9}$ and Szczukiewicz et al.), ${ }^{10}$ which provide higher upstream pressure drop, promote the downstream flow of the vapor bubble and suppress the vapor backflow.

Another approach to reduce flow instabilities is to fabricate potential nucleation sites. This precaution mea- 
sure lowers the fluid superheat required for ONB and therefore also slows down the vapor bubble growth, which induces less explicit vapor backflows. Nucleation sites can be easily etched in silicon, though recent advances in micro-engineering allow similar feature geometries to be machined in a wider range of materials as it was demonstrated by Kandlikar, ${ }^{11}$ Liu et al., ${ }^{12}$ Sabotin et al. ${ }^{13}$ and Balasubramanian et al. ${ }^{14}$ The dimensioning of the potential nucleation cavities should consider the nucleation criteria, which were initially modeled by $\mathrm{Hsu}^{15}$ and afterwards also by Kandlikar et al. ${ }^{16}$

Several authors have analyzed fluctuations during boiling from pressure or temperature measurements $\mathrm{Mu}-$ wanga et al., ${ }^{17}$ Zhang et al., ${ }^{18}$ Tuo and Hrnjak, ${ }^{19}$ Liu et al.). ${ }^{20}$ In a single microchannel experiments the boiling instabilities could be distinctly manifested in the pressure measurements, if the pressure sensor is located close enough to the boiling process. However, pressure and temperature measurements in a single microchannel unambiguously indicate only the oscillation frequencies, whereas the amplitudes of the oscillating meniscus during boiling are more difficult to interpret from the measurements. Consequently, the boiling front oscillations in the manufactured microchannels were analyzed from the results of visualization, as the pressure/temperature measurements are insufficient.

The published experimental results regarding heat flux and/or temperature effect on the bubble frequency during pool and flow boiling are ambiguous. On one hand, Gerardi et al. ${ }^{21}$ investigated pool boiling of water and nanofluids with an infrared camera and found a strong dependence of the bubble departure frequency on the wall superheat. Additional confirmation of the heat flux strong effect on the departure frequency in pool boiling is seen from the experimental results conducted by Dong et al. ${ }^{22}$ On the other hand, Kim et al. ${ }^{23}$ incorporated nanowires to the boiling surface and their results show a small to no significant effect of heat flux on the bubble detaching frequency on the plain or enhanced silicon surface. Similar results of the bubble nucleation frequency with small dependence on the wall superheat in pool boiling was presented in Hutter et al. ${ }^{24} \mathrm{~A}$ small effect of the heat flux on the nucleation frequency during vertical subcooled flow boiling was encountered by $\mathrm{Chu}$ et al. ${ }^{25}$

The employment of numerical analysis to flow boiling in microchannels is being studied by various research groups, however a fully functional numerical model is still far from being reached due to the complexity of the boiling phenomena. Numerical modelling of pressures, temperatures and velocities is commonly associated with twophase non-boiling flows Cioncolini and Thome, ${ }^{26}$ specific flow patterns in predominantly larger circular microchannels Magnini and Thome ${ }^{27}$ single bubble growth and bubble merger in larger square microchannels Mukherjee et al. ${ }^{28}$ and Ling et el., ${ }^{29}$ single bubble analysis Ferrari et al., ${ }^{30}$ and is therefore not entirely relatable to the solely annular flow observed during boiling in our experimental work.
Another approach is a mechanistic model presented by $\mathrm{Pa}$ tel et al., ${ }^{31}$ which covers a two-phase flow of air and water and would need some tailoring to model the bubble shapes and heat transfer coefficients during flow boiling.

The current study was focused on detecting the instabilities with high speed imaging, which were afterwards analyzed in order to evaluate the amplitudes and the fundamental frequencies of the oscillations and the effect of the working conditions on flow boiling. Similar research of boiling dynamics in microchannels was not found in the reviewed literature, moreover some of the published work have contradictory conclusions. The presented experimental work and analysis aim at determining the flow boiling characteristics in microchannels to allow an improved construction of the future two-phase micro devices.

\section{Experimental Setup and Test Section}

A simplified schematic diagram of the experimental setup employed for visualization and measurements is presented in Figure 1, whereas the complete wiring with the details of the measurement equipment is available in $\mathrm{Si}$ tar et al. ${ }^{9}$ The visualization system is comprised of a microscope, a powerful light source and a high-speed camera.

Temperature, pressure, and heat transfer rate were measured simultaneously while the visualization system acquired dynamics of the bubble nucleation, growth, and oscillations during boiling in microchannels. Heat flux $q$ was determined from the heater surface $A_{h}$ and the heat transfer rate $Q_{h}$, which was calculated according to the equation

$$
Q_{h}=U_{h} \frac{U_{s h}}{R_{s h}}
$$

where $R_{s h}$ is the electrical resistance of the incorporated reference shunt, $U_{h}$ and $U_{s h}$ are the voltage drops across the heater and shunt, respectively. The shunt included had an electrical resistance of $0.05 \Omega \pm 0.25 \%$. The measured voltage signal passed through the amplification module and the data acquisition board, both of which introduce a measurement uncertainty in linear dependence of the measured voltage signal. The combined expanded relative temperature measurement uncertainty $W(T)$ with a $95 \%$ level of confidence was determined to be $1.5 \%$ in the range from $50{ }^{\circ} \mathrm{C}$ to $200{ }^{\circ} \mathrm{C}$, whereas $W\left(Q_{h}\right)$ was calculated to be from $6.6 \%$ to $4.6 \%$ for the heat rates ranging in between $6.9 \mathrm{~W}$ and $16 \mathrm{~W}$. These heat rates correspond to heat fluxes from $150 \mathrm{~kW} / \mathrm{m}^{2}$ to $350 \mathrm{~kW} / \mathrm{m}^{2}$, respectively. The combined expanded absolute measurement uncertainty of the pressure measurements $U(p)$ was $65 \mathrm{mbar}$ up to the measured gauge pressure of $4 \mathrm{bar}$ in the test section. The details of the measurement uncertainty analysis was presented in Sitar and Golobič. ${ }^{32}$ 


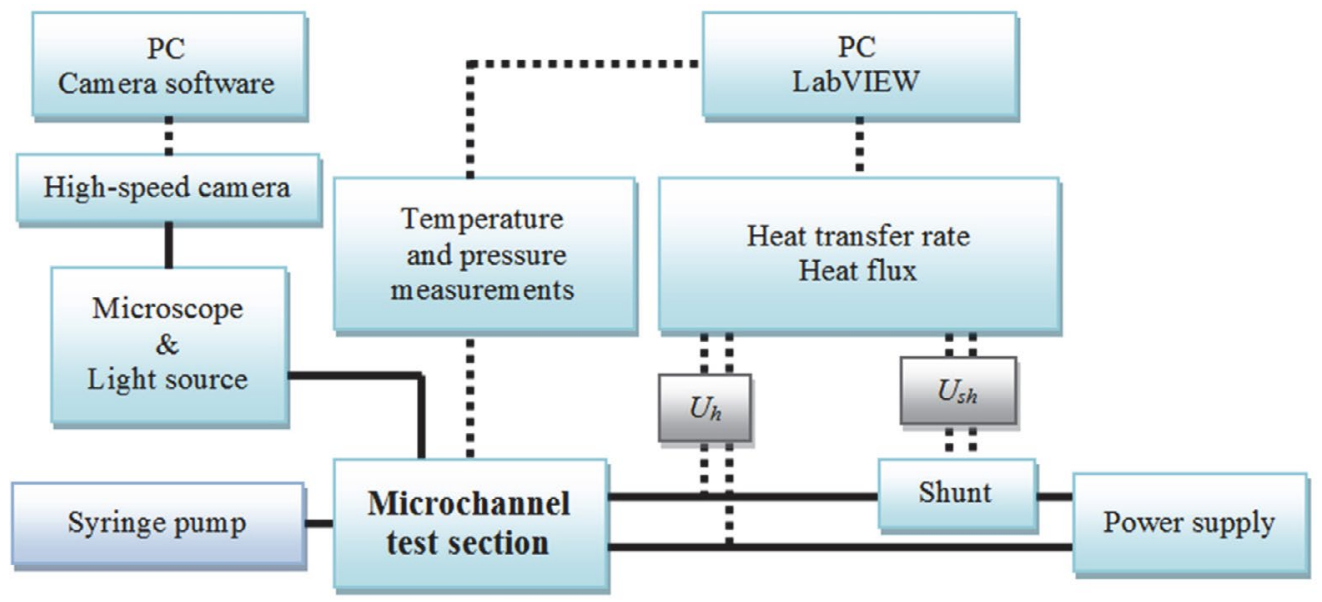

Figure 1. Experimental setup.

Degassed double-distilled water was the working fluid in all experiments which were conducted in single 50 $\times 50 \mu \mathrm{m}$ and $100 \times 50 \mu \mathrm{m}$ (width $\times$ depth) microchannels, which is presented schematically in Figure 2. In the microchannel test sections the inlet/outlet channel with the width of $1 \mathrm{~mm}$ was gradually narrowed to the final width of $50 \mu \mathrm{m}$ or $100 \mu \mathrm{m}$. Water was pumped through the microchannels at a constant volumetric flow from the left to the right hand side of the microchannel test section.

The used microchannels had smooth walls and bottom without any tailored potential nucleation sites. The only additional feature in the single microchannels was the inlet restrictor with a cross section of $20 \times 50 \mu \mathrm{m}$.

The high-speed visualizations and measurements were performed simultaneously at a steady-state, which was defined as a state with the measured temperatures change of less than $2 \mathrm{~K}$ during a $10 \mathrm{~min}$ period. The temperature measurements were done at the bottom side of the silicon wafer in the middle of the microchannel, 9.7 $\mathrm{mm}$ upstream (inlet temperature) and $9.7 \mathrm{~mm}$ downstream (outlet temperature) of the middle of the test section. The gauge pressure was measured at the inlet of the microchannels, whereas the outlet of the test section is presumed to be at atmospheric pressure.

\section{Digital Image Sequence Analysis}

In each experiment sets of up to 100,000 images were acquired and stored. In order to determine time depen-

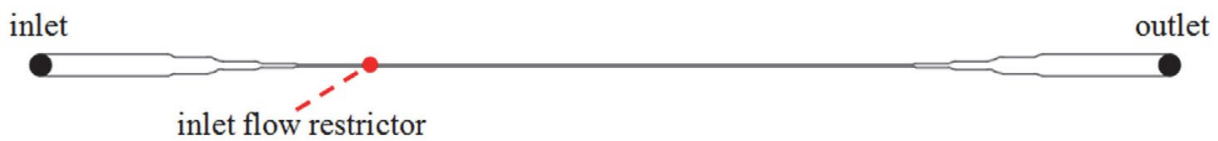

Figure 2. Design of a single microchannel with an inlet flow restrictor.

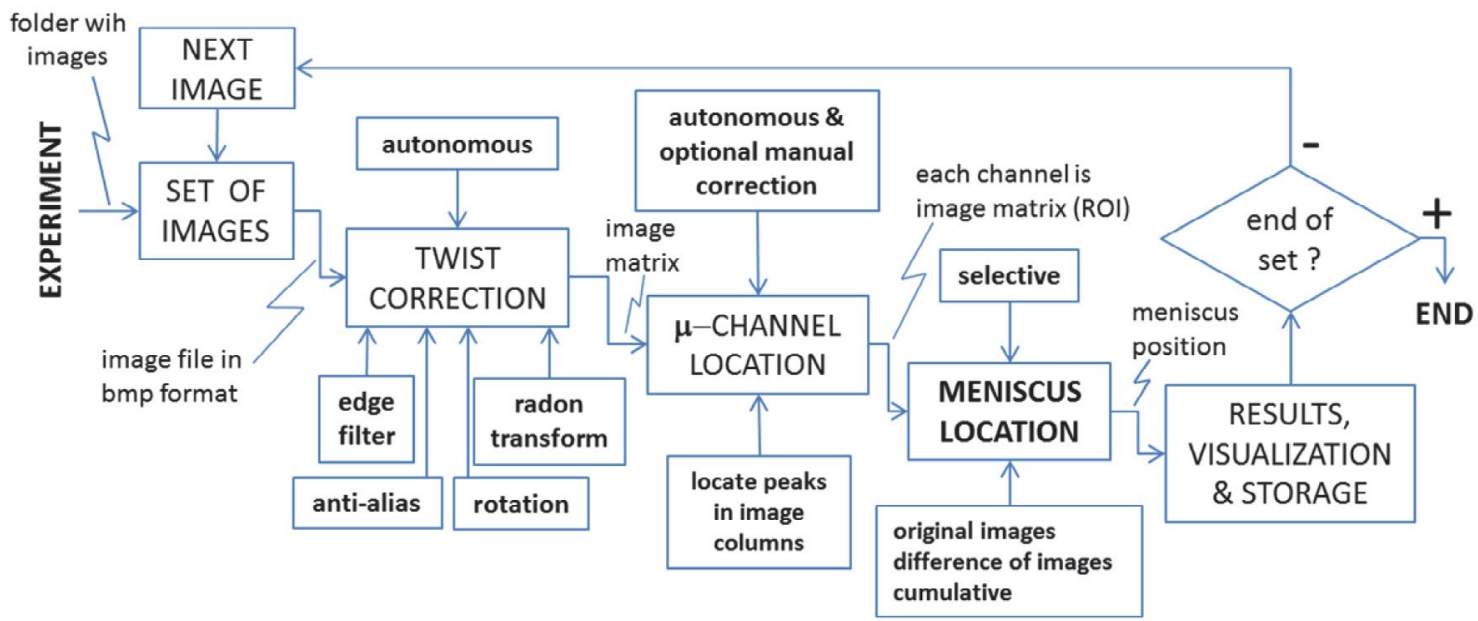

Figure 3. Functional diagram of the digital image sequence analysis. 
dence of the meniscus location, a digital image procedure was applied to each set. In Figure 3 the analysis workflow is given in the form of a functional diagram, which is to be explained in the following. Image analysis was performed completely in the Matlab environment.

Due to manipulation of the test section and the camera during experiments a small undesired twist of the microchannel array coordinate system towards the coordinate system of the camera occurred, which was evaluated by using Radon transform and consequently corrected by image rotation.

Next task in the workflow diagram (Figure 3) was to find the locations of microchannels, which are marked with green dots in the Figure 4. Locations were determined by locating the darkest points in a single column of the image matrix.

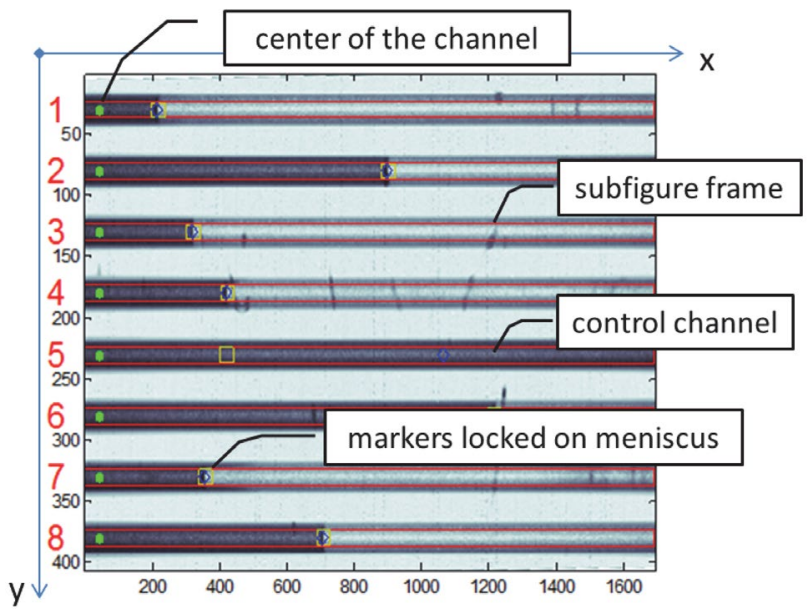

Figure 4. Labeled microchannels and automatically determined centers of the channels (green dots).

After the microchannel centers were known, each channel was identified as a region of interest (ROI) determined by the boundary indexes in the image matrix, which were calculated from the microchannel centers and channel width.

Determination of the meniscus location is the core function of image sequence analysis workflow (Figure 5).
Initially it was based on the straightforward fact that the image brightness changes significantly at the border between the liquid and vapor phase, as it is seen in Figure 5 (a). In order to decrease brightness variations (noise) along the microchannel, a cumulative sum of columns in ROI was calculated, which is given in Figure 5 (b). Location of the meniscus is then determined by applying a threshold and the first point which exceeds the threshold is the location of the meniscus.

An improvement of the discussed method is to compute the derivative of the brightness variation, as it can be observed in Figure 5 (c). The highest peak is expected to correspond to the meniscus location. Several partially unavoidable challenges have been found in locating the meniscus location: bubbles nucleating upstream of meniscus, microchannel surface features, potential dust and stains etc. In order to overcome this challenge, an analysis was performed on the differences of the consecutive images instead of on just one single image. Brightness variation and derivative of image brightness variation was observed. The difference of consecutive images from the example presented in Figure 5 is shown in Figure 6.

Analysis of the meniscus location on the differences of images yielded more reliable results. Despite the significant improvement, analysis failed to track the meniscus properly in cases with many bubbles emerging upstream.

a)

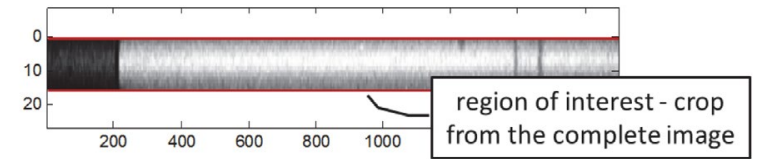

b)

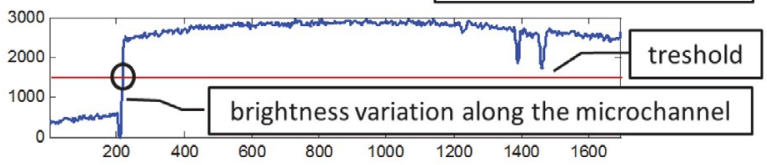

c)

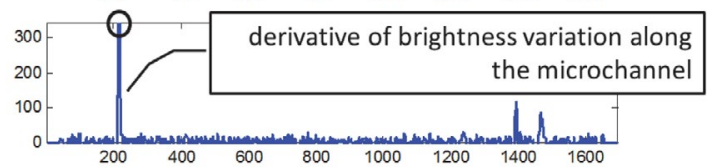

Figure 5. Identification of the meniscus location - a) ROI of channel \#1 cropped from the complete image (Figure 5); b) brightness variation; c) derivative of the brightness variation.

Figure 6. Subtraction of consecutive images.

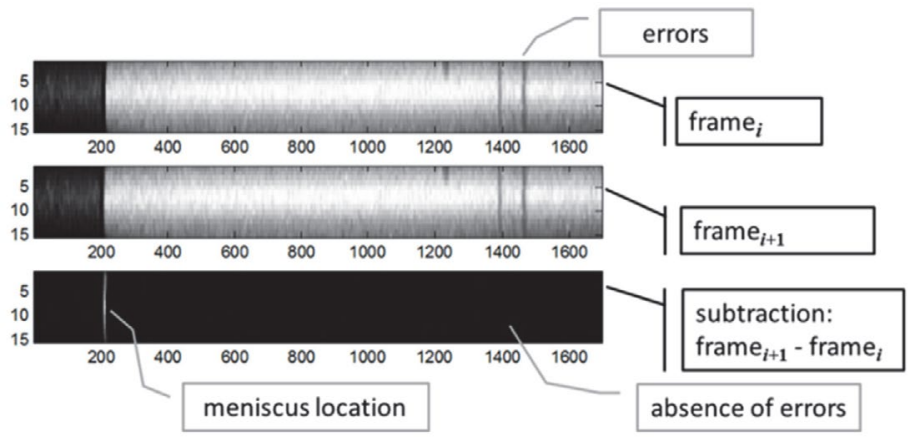

Figure 6. Subtraction of consecutive images. 
In those cases all of the image pixel values in ROI were summed. If the channel was full of water it was overall dark and the sum of all the pixel values was smaller. Inversely the sum of pixel values was higher if the channel was filled with vapor. Consecutive summation values were stored in an array for further analysis. This method yielded very smooth and reliable results, which can be used for fundamental frequency analysis.

The developed digital sequence analysis is capable of tracking meniscus location in an array of microchannels, while the operation of the algorithm is simplified during image analysis of the single channel experiments. Due to better positioning of the experimental setup, rotation correction was omitted and due to the improved illumination, meniscus location was determined based on brightness variation detection similar as in Figure 5 (b).

\section{Results and Discussion}

The primary goal of any two-phase heat transfer device is an efficient heat transfer as well as a stable and predictable behavior during operation. Flow boiling in microchannels is often accompanied by instabilities and vapor backflows, which inhibit constant flow of the working fluid and reduce the heat transfer.

The ONB was achieved at higher temperatures compared to our previous experimental work in an array of microchannels, due to the smooth walls and bottom of the single microchannels. Consequentially, the temperature and heat flux were increased until ONB was reached at temperatures from $140^{\circ} \mathrm{C}$ to $160^{\circ} \mathrm{C}$ in the middle of the microchannel. Afterwards, the heat flux was stepwise lowered and the data was acquired at a steady-state point along with the high-speed image acquisition. The comparison of the measured temperatures and pressures for the same volumetric flow of $0.2 \mathrm{ml} / \mathrm{min}$ in a microchannel with a cross-section of $50 \times 50 \mu \mathrm{m}$ and $100 \times 50 \mu \mathrm{m}$ is presented in Figure 7 . The results are undoubtedly showing lower inlet gauge pressure and also temperatures at all three measured location in the microchannel with the larger cross-section. The inlet gauge pressure was lowered from 2.81 bar to 0.88 bar during the single-phase flow in the $50 \times 50 \mu \mathrm{m}$ microchannel, and was raised up to $3.44 \mathrm{bar}$ at the ONB at $14.6 \mathrm{~W}$ of heating power. The measured gauge pressure in the larger $100 \times 50 \mu \mathrm{m}$ microchannel was initially 1.26 bar and lowered down to 0.51 bar prior to the ONB, which then caused the elevation of the gauge pressure up to $2.56 \mathrm{bar}$.

The results of high-speed visualizations were analyzed to establish the characteristics of oscillations, especially the peak to peak amplitude and the frequency of the meniscus during boiling. The location of the liquid-vapor boundary was determined according to the presented digital image sequence analysis. Afterwards, the amplitude of the oscillations and FFT was derived from the acquired data to determine the fundamental frequencies. Figure 8 depicts a small portion of the performed FFT analysis in a $50 \times 50 \mu \mathrm{m}$ microchannel at volumetric flow of $0.2 \mathrm{ml} /$ $\mathrm{min}$. The presented data confirms that the oscillations in the single microchannel were periodic at all the presented temperatures, as the fundamental frequencies could be undoubtedly and accurately determined from the FFT.

The fundamental frequencies and the corresponding peak to peak amplitudes of all the observed oscillations in single microchannels with a cross section of $50 \times 50 \mu \mathrm{m}$ and $100 \times 50 \mu \mathrm{m}$ are presented in Figure 9. The framerates of the high-speed visualizations varied from 10,000 to $100,000 \mathrm{fps}$ and were adapted to allow proper observation of the boiling process. The experimental results were approximated with a first order inverse polynomial function and the approximation curve is similar in both microchannels. However, a detailed comparison of the experimental results showed a maximum oscillation frequency in the $50 \times 50 \mu \mathrm{m}$ microchannel to be above $20 \mathrm{kHz}$,

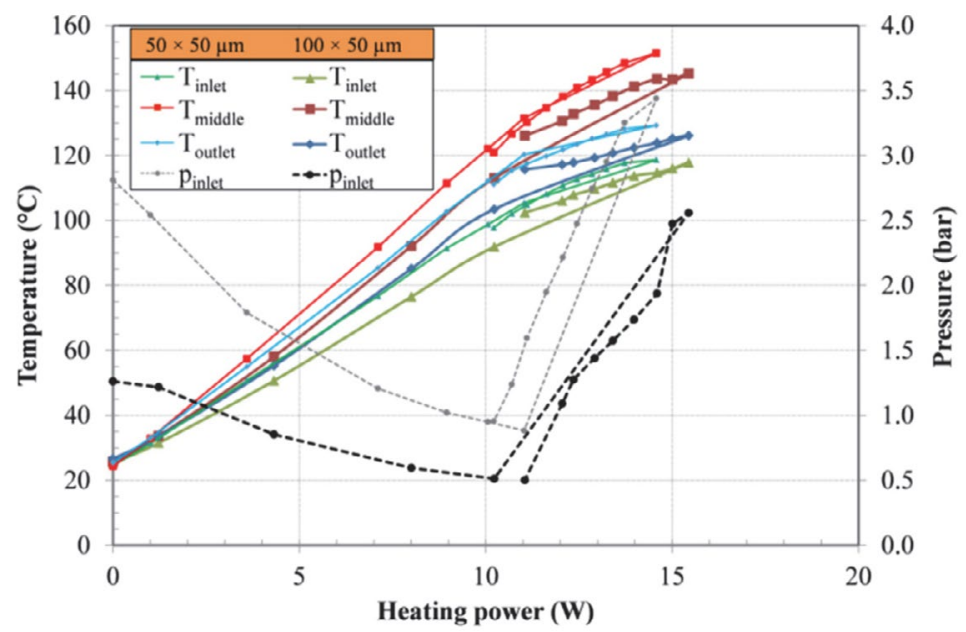

Figure 7. Comparison of temperatures and pressures in a single $50 \times 50 \mu \mathrm{m}$ and $100 \times 50 \mu \mathrm{m}$ microchannel at the same volumetric flow of $0.2 \mathrm{ml} /$ min. 

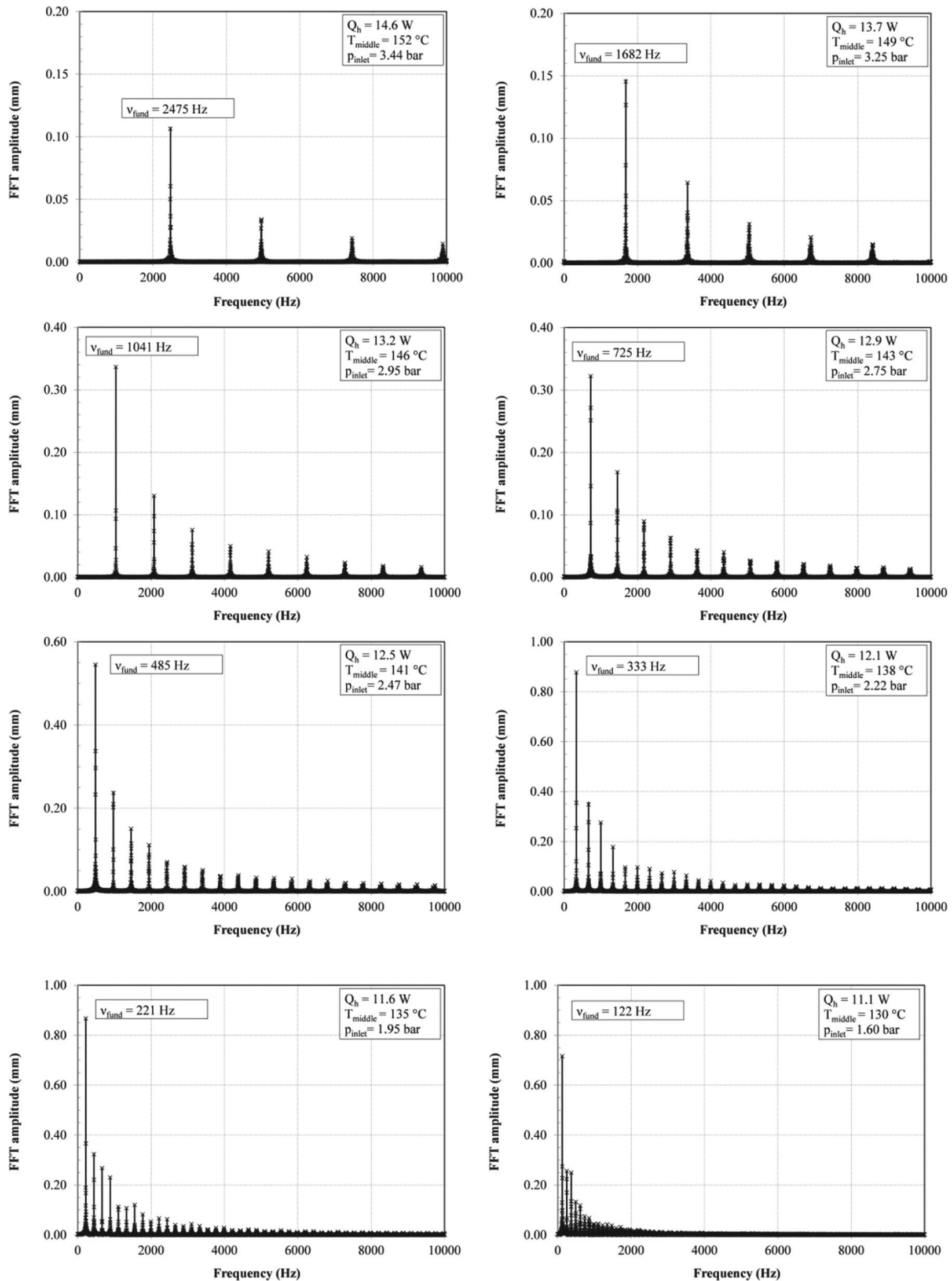

Figure 8. FFT analysis of meniscus oscillations during boiling in a single $50 \times 50 \mu \mathrm{m}$ microchannel at temperatures ranging from $152^{\circ} \mathrm{C}$ to $130{ }^{\circ} \mathrm{C}$ in the middle of the microchannel. 


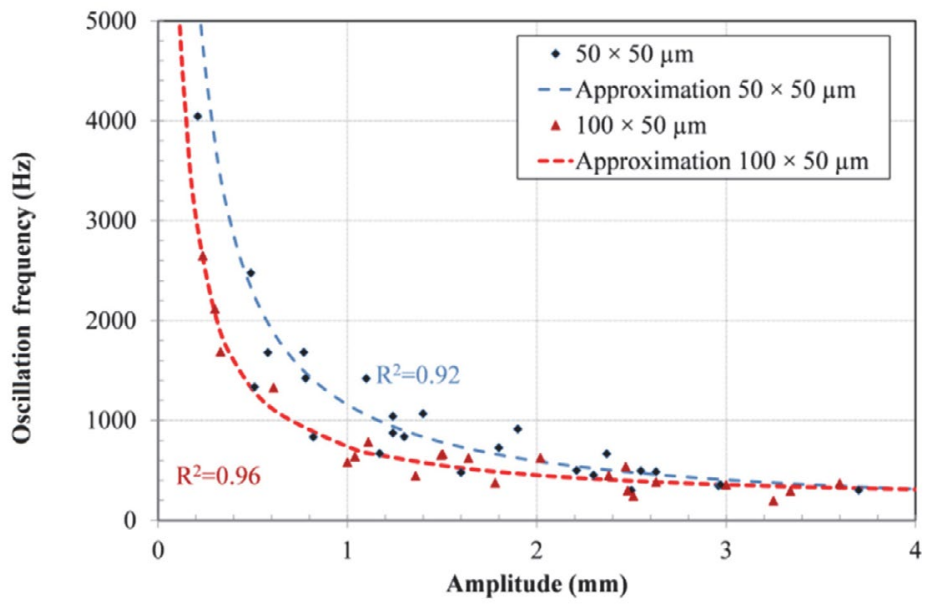

Figure 9. Oscillation frequency dependence on oscillation amplitude in a single $50 \times 50 \mu \mathrm{m}$ and $100 \times 50 \mu \mathrm{m}$ microchannel.

whereas the maximum frequency recorded in the $100 \times 50$ $\mu \mathrm{m}$ was $2.65 \mathrm{kHz}$.

Despite the difference between the highest fundamental frequencies observed at the ONB in single microchannels, there is an undeniable similarity in the frequen- cy-amplitude dependency. The basis of the similar behavior of the boiling water originates from the reciprocal nature of the frequency-amplitude relationship. The fundamental frequencies of oscillations during boiling was found to be inversely dependent on the amplitudes by Ivey, ${ }^{33}$ which is

a)

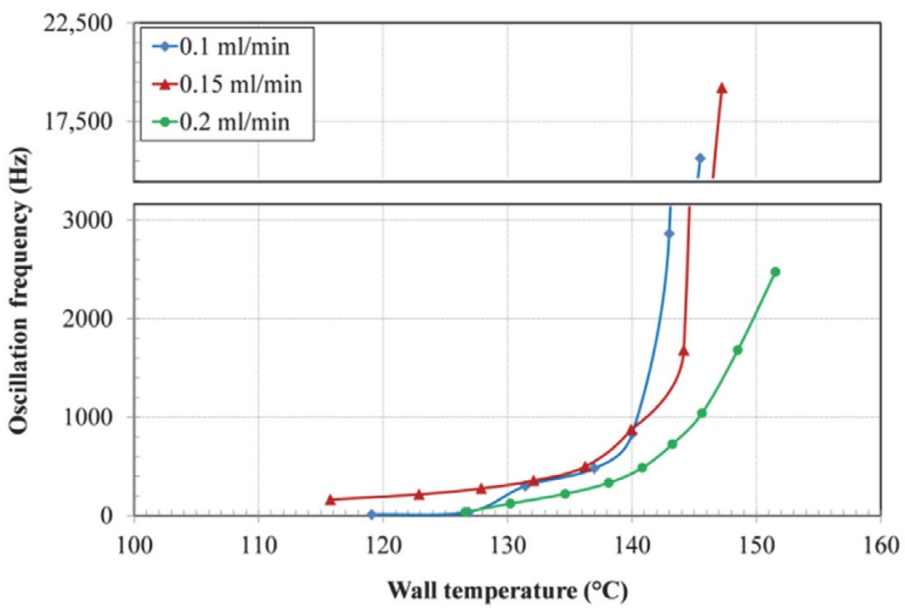

b)

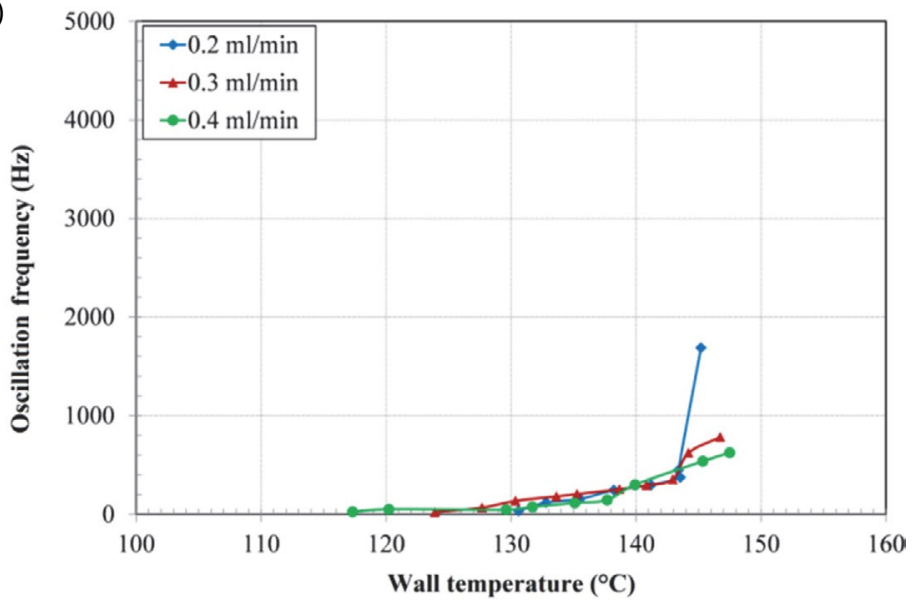

Figure 10. Oscillation frequency dependence on wall temperature at various volumetric flows in a single (a) $50 \times 50 \mu \mathrm{m}$ and (b) $100 \times 50 \mu \mathrm{m}$ microchannel. 
experimentally validated also for flow boiling in microchannels in Figure 9. The largest amplitudes were recorded at the lowest frequencies as the meniscus shifts further downstream if there is more time available before another bubble nucleates.

The effect of the wall temperature in the middle of the microchannels on the fundamental frequencies is presented in Figure 10. The experiments performed in the $50 \times 50 \mu \mathrm{m}$ microchannel are given in Figure 10 (a) at three volumetric flows. The highest fundamental frequency was almost $21 \mathrm{kHz}$ at the $\mathrm{ONB}$ at $147^{\circ} \mathrm{C}$ with the water volumetric flow set to $0.15 \mathrm{ml} / \mathrm{min}$. The wall temperature had similar effect on the oscillation frequencies also in the $100 \times 50 \mu \mathrm{m}$ microchannel, as it is seen in Figure 10 (b).

However, the maximum achieved fundamental frequencies of the boiling oscillations were significantly lower in the microchannel with the larger cross-section, which implicates that the characteristics of oscillations are fairly well connected to the size of the microchannel. Generally, the frequencies were lowering with decreasing heat transfer rate and temperature for all of the performed experiments. In addition, the effect of the various mass fluxes on the fundamental frequencies is not seen from the experimental results in Figure 10.

\section{Conclusions}

Flow boiling of degassed water was visualized in single $50 \times 50 \mu \mathrm{m}$ and $100 \times 50 \mu \mathrm{m}$ microchannels. The results confirm periodical oscillations at all the measured steady state points. The analysis of the experimental results of temperature, pressure and heat transfer rate consistently shows that (i) higher volumetric flow; (ii) smaller microchannel cross-section and (iii) the presence of boiling are followed by a significant increase of the pressure drop in the microchannel. The fundamental frequency and peak to peak amplitude of oscillations were found to be inversely proportional in both single microchannels included in the research. The onset of boiling was achieved at relatively high wall temperatures from $140{ }^{\circ} \mathrm{C}$ to $160^{\circ} \mathrm{C}$ due to the absence of properly sized nucleation sites. The recorded oscillation frequencies reached above $20 \mathrm{kHz}$ in the $50 \times 50 \mu \mathrm{m}$ microchannel and were the highest at the ONB as the heat transfer rate and temperature was afterwards gradually decreased. The highest fundamental frequency in the larger $100 \times 50 \mu \mathrm{m}$ microchannel at a steady-state was approximately $2 \mathrm{kHz}$, which demonstrates the effect of the microchannel size on the boiling characteristics. In the presented literature for pool boiling the nucleation frequencies are several orders lower compared to our experimental results in microchannels. The fundamental frequency of boiling was consistently and significantly lowering and the amplitude was increasing with decreasing temperature and heat transfer rate for both analyzed single microchannels.
The boiling regime observed in the microchannels was for the most part limited to annular flow, as the cross-section of the channels was too small for the formation of a bubbly, slug or churn flow. Additionally, the meniscus between the liquid and vapor phase was oscillating with a frequency related to the bubble nucleation frequency, which further depends on the working fluid, the available sizes of the nucleation sites, the temperature, etc.

The effect of the wall superheat and heat flux on the characteristics of flow boiling in microchannels is evident from the results presented, which is crucial for developing and designing future two-phase heat transfer devices. Namely, the wall temperature and microchannel size along with other working conditions are determining the length of the microchannel in which liquid and vapor phase are periodically altered. Heat is transferred substantially more efficient over this length compared to all the other surfaces of the microchannel, as the latent heat of the working fluid is exploited solely in this section of the microchannels. Therefore, the amplitudes and frequencies of the oscillating meniscus are important parameters of the performance of two-phase micro devices. Higher heat fluxes demand shorter lengths of microchannels for efficient heat transfer, which could be achieved with a larger number of inlets and outlets. Future work should broaden the controlled working conditions to analyze their effect on oscillations during boiling and consequentially on heat transfer. Researchers in the field of micro two-phase devices such as micro heat exchangers or micro reactors should consider the effect of the working conditions on flow boiling in microchannels and adapt their designs accordingly.

\section{References}

1. S. G. Kandlikar, S. Colin, Y. Peles, S. Garimella, R. F. Pease, J. J. Brandner, D. B. Tuckerman, J. Heat Transfer 2013, 135, 091001-091018. DOI:10.1115/1.4024354

2. S. M. Ghiaasiaan, R. C. Chedester, Int. J. Heat Mass Transfer 2002, 45, 4599-4606. DOI:10.1016/S0017-9310(02)00167-9

3. S. G. Kandlikar, Heat Transfer Engineering 2010, 31, 159-167. DOI:10.1080/01457630903304335

4. Z. J. Edel, A. Mukherjee, Int. J. Multiphase Flow 2011, 37, 1257-1265. DOI:10.1016/j.ijmultiphaseflow.2011.07.007

5. J. Barber, D. Brutin, K. Sefiane, J. L. Gardarein, L. Tadrist, Int. J. Heat Mass Transfer 2011, 54, 4784-4795.

DOI:10.1016/j.ijheatmasstransfer.2011.06.026

6. S. G. Kandlikar, D. A. Willistein, J. Borrelli, 2005, pp. 115-124.

7. C. J. Kuo, Y. Peles, Int. J. Heat Mass Transfer 2007, 50, 45134526. DOI:10.1016/j.ijheatmasstransfer.2007.03.047

8. G. Wang, P. Cheng, A. E. Bergles, Int. J. Heat Mass Transfer 2008, 51, 2267-2281.

DOI:10.1016/j.ijheatmasstransfer.2007.08.027

9. A. Sitar, I. Sedmak, I. Golobic, Int. J. Heat Mass Transfer 2012, 55, 6446-6457.

DOI:10.1016/j.ijheatmasstransfer.2012.06.040 
10. S. Szczukiewicz, N. Borhani, J. R. Thome, Int. J. Heat Fluid Fl. 2013, 42, 176-189.

DOI:10.1016/j.ijheatfluidflow.2013.03.006

11. S. G. Kandlikar, Applied Physics Letters 2013, 102, 051611051611-051611-051615.

12. K. Liu, B. Lauwers, D. Reynaerts, Int J Adv Manuf Technol 2010, 47, 11-19. DOI:10.1007/s00170-009-2056-1

13. I. Sabotin, G. Tristo, M. Junkar, J. Valentinčič, Chemical Engineering Research and Design 2013, 91, 778-788.

DOI:10.1016/j.cherd.2012.09.013

14. K. Balasubramanian, P. S. Lee, C. J. Teo, S. K. Chou, Int. J. Heat Mass Transfer 2013, 67, 234-252.

DOI:10.1016/j.ijheatmasstransfer.2013.08.023

15. Y. Y. Hsu, J. Heat Transfer 1962, 84, 207-216. DOI:10.1115/1.3684339

16. S. G. Kandlikar, V. R. Mizo, M. D. Cartwright, E. Ikenze, Proc. HTD-Vol. 342, ASME Proceedings of the 32nd National Heat Transfer Conference, 1997, pp. 11-18.

17. R. Muwanga, I. Hassan, R. MacDonald, J. Heat Transfer 2007, 129, 1341-1351. DOI:10.1115/1.2754946

18. T. Zhang, Y. Peles, J. T. Wen, T. Tong, J.-Y. Chang, R. Prasher, M. K. Jensen, Int. J. Heat Mass Transfer 2010, 53, 2347-2360. DOI:10.1016/j.ijheatmasstransfer.2010.02.005

19. H. Tuo, P. Hrnjak, Int. J. Heat Mass Transfer 2014, 71, 639652. DOI:10.1016/j.ijheatmasstransfer.2013.10.024

20. Y. Liu, D. F. Fletcher, B. S. Haynes, Int. J. Heat Mass Transfer 2013, 58, 503-512.

DOI:10.1016/j.ijheatmasstransfer.2012.11.068

21. C. Gerardi, J. Buongiorno, L.-w. Hu, T. McKrell, Nanoscale Research Letters 2011, 6, 232. DOI:10.1186/1556-276X-6-232
22. L. Dong, X. Quan, P. Cheng, Int. J. Heat Mass Transfer 2014, 71, 189-196. DOI:10.1016/j.ijheatmasstransfer.2013.11.068

23. B. S. Kim, S. Shin, D. Lee, G. Choi, H. Lee, K. M. Kim, H. H. Cho, Int. J. Heat Mass Transfer 2014, 70, 23-32.

DOI:10.1016/j.ijheatmasstransfer.2013.10.061

24. C. Hutter, A. Sanna, T. G. Karayiannis, D. B. R. Kenning, R. A. Nelson, K. Sefiane, A. J. Walton, Exp. Therm. Fluid Sci. 2013, 51, 94-102. DOI:10.1016/j.expthermflusci.2013.07.005

25. I.-C. Chu, H. C. No, C.-H. Song, Journal of Nuclear Science and Technology 2011, 48, 936-949. DOI: $10.1080 / 18811248.2011 .9711780$

26. A. Cioncolini, J. R. Thome, Int. J. Multiphase Flow 2017, 89, 321-330. DOI:10.1016/j.ijmultiphaseflow.2016.11.003

27. M. Magnini, J. R. Thome, Int. J. Multiphase Flow 2017, 91, 296-314. DOI:10.1016/j.ijmultiphaseflow.2017.01.015

28. A. Mukherjee, S. G. Kandlikar, Z. J. Edel, Int. J. Heat Mass Transfer 2011, 54, 3702-3718.

DOI:10.1016/j.ijheatmasstransfer.2011.01.030

29. K. Ling, G. Son, D.-L. Sun, W.-Q. Tao, Int. J. Therm. Sci. 2015, 98, 135-147. DOI:10.1016/j.ijthermalsci.2015.06.019

30. A. Ferrari, M. Magnini, J. R. Thome, Int. J. Heat Mass Transfer 2018, 123, 928-944.

DOI:10.1016/j.ijheatmasstransfer.2018.03.012

31. R. S. Patel, J. A. Weibel, S. V. Garimella, Int. J. Heat Mass Transfer 2017, 114, 841-851.

DOI:10.1016/j.ijheatmasstransfer.2017.06.121

32. A. Sitar, I. Golobic, Int. J. Heat Mass Transfer 2015, 81, 198 206. DOI:10.1016/j.ijheatmasstransfer.2014.10.034

33. H. J. Ivey, Int. J. Heat Mass Transfer 1967, 10, 1023-1040. DOI:10.1016/0017-9310(67)90118-4

\section{Povzetek}

$\mathrm{Na}$ osnovi eksperimentalnih rezultatov in vizualizacije s hitrotekočo kamero smo analizirali konvektivno vrenje razplinjene redestilirane vode v enojnih $50 \times 50 \mu \mathrm{m}$ in $100 \times 50 \mu \mathrm{m}$ mikrokanalih. Vrenje smo parametrizirali glede na vizualizirane frekvence pojavljanja mehurčkov oz. oscilacije vrelne fronte. Izdelali smo računalniški algoritem za zaznavanje lokacije mehurčkov in meniskusa med parno in kapljevito fazo. Rezultati kažejo, da (i) je vrenje v mikrokanalih dinamičen proces, (ii) se lastne frekvence nihanja povišujejo s povečevanjem gostote toplotnega toka in temperature na dnu mikrokanala, (iii) so amplitude nihanja med vrenjem inverzno sorazmerne lastnim frekvencam nihanja. $\mathrm{Z}$ raziskavo smo eksperimentalno potrdili, da so nihanja med vrenjem $\mathrm{v}$ enojnih mikrokanalih predvidljiva $\mathrm{z}$ vidika trendov in odvisnosti lastne frekvence ter amplitude nihanja. Poznavanje procesa vrenja je še posebej pomembno pri konstruiranju učinkovitih dvofaznih mikro prenosnikov toplote, mikro mešalnikov ali mikro reaktorjev. Namreč, v mikro napravah, ki vključujejo vrenje, postaneta presek in dolžina kanala izjemno pomembna parametra za uspešno načrtovanje učinkovite naprave. 